\title{
The Forms of Value: Problems of Convertibility in Field Theory
}

\author{
Göran Bolin
}

\author{
Södertörn University, Stockholm, Sweden, goran.bolin@sh.se
}

\begin{abstract}
Media production in late capitalism is often measured in terms of economic value. If value is defined as the worth of a thing, a standard or measure, being the result of social praxis and negotiation between producers and consumers in various combinations, it follows that this worth can be of other kinds than the mere economic. This is, for example, the reasoning behind field theory (Bourdieu), where the generation of field-specific capital (value) is deeply dependent on the belief shared by the competing agents within the field. The full extent of the consequences of such a theory of convertibility between fields of cultural production, centred on different forms of value, is, however yet to be explored. This is the task of this article. It especially focuses on how value is constructed differently depending on the relations of the valuing subject to the production process, something that becomes highly relevant in digital media environments, where users are increasingly drawn into the production process.
\end{abstract}

Keywords: Value, Field Theory, Capital, Media Production, Bourdieu

\section{Field Theory and Digital Economies}

In late modern digital economies - where the relations of cultural production and consumption are increasingly intertwined; where the labour of production and consumption is often increasingly being carried out by the same individuals (although not at the same time, and often not within the same frameworks); and where the values attached to the objects produced and consumed are increasingly subsumed under economic logics - we need refined tools to analyse these complex relations. How can we understand the deeper relations between cultural production and consumption in digital markets? Or, more precisely, how can we understand the production of various kinds of value in relation to cultural production and consumption? And why is it that we constantly fall back into economic reasoning when evaluating cultural objects and practices? This article proposes a conceptual toolbox for the understanding of these questions, based on the field theory of Pierre Bourdieu but with significant modifications and updates for the digital world. In suggesting this toolbox, the article also offers a thorough critique (in the Kantian sense) of the field theory, in order to advance it beyond some of its present limitations. This means also that one needs to return to some of the influences of the field theory, to trace the theoretical influences from Karl Marx, Émile Durkheim and Marcel Mauss.

The field theory of Bourdieu, perhaps most elaborated in The Rules of Art (1992/1996) and The Field of Cultural Production (1993), has proven to be a useful tool in the analysis of cultural and media production over the past decade. Field theoretical perspectives have been used for empirical analysis of the music industry (e.g. Hesmondhalgh 1996, 1999 and 2006), journalism (Benson 1999, Benson \& Neveu 2005, Schultz 2005), media systems (Hallin and Mancini 2004), but also for the analysis of media's power of constructing reality more generally, as in Nick Couldry's (2000, 2003a and 2003b) highly original work on media institutions and symbolic power. A reason for this rising popularity might be that the field theory addresses explicitly the relations between production and consumption, thus addressing increasingly pressing questions within media and communications research, thereby avoiding the reductionism of only focusing on one part of the productionconsumption circuit. These questions are to a very high degree connected to the process of digitisation, and the consequences of the increasing spread not only of the means of consumption, but also and simultaneously, of means of production (see Bolin 2009 and 2011 for more elaborate accounts of the merging of the means of consumption and production).

Many of these studies have also tried to overcome some of the weaknesses in Bourdieu's theory, most notably its relative neglect, or, to put it more mildly, its disinterest in the unrestricted and undifferentiated production of mass or popular culture. Since Bourdieu's field model is structured according to oppositions between the cultural and the economic, and between the established producers and their challengers, Bourdieu has been more interested in the dominating part of the field, where agents uphold dominant positions, and where the capital (or value, as I will ar- 
gue) at the centre of the struggle within the field is strongest and therefore most distinctive. In this part of the field, producers are more autonomous than the producers in the dominated part of the field, where success is measured not on the terms of the field itself, but according to terms set by the value logics of other fields. Most often these logics stem from the field of the economy, as Bourdieu insistently argues the structural opposition between culture and commerce.

This article aims to add to this critique of Bourdieu's field theory, through analysing more thoroughly its core concept of capital, and its economistic bias, including the idea of convertibility between fields. My basic argument is [1] that what Bourdieu means when speaking of 'capital' is really 'value', and [2] that the roots of his theory in Marx' labour theory of value poses some problems for his theory (and especially his theory of convertibility between forms of capital). By this I am not saying that we should abandon field theory because I do argue that it has some advantages over competing paradigms (depending on your aims, of course). But I think we need to qualify and reinstall the concept of value to his theory, in order, firstly, to more thoroughly develop the analysis of unrestricted and undifferentiated cultural production, and secondly, to overcome the tendency to relate all value forms to economic value.

In the following, I will develop such an argument, beginning with an epistemological justification for why this discussion is of interest. This justification leads, in the same section, to the presentation of Bourdieu's field model, the criticism one can raise against it, and the qualifications to it that I suggest. I then give account for the Marxist legacy of Bourdieu's theory, in order to, in the section following that, discuss the terminological confusion between capital and value in Bourdieu's theory, and how the theory actually benefits from using value rather than capital. In this last section, I will also explain why this is of crucial importance if we are to understand the digital markets of the present. The argument builds on, and extends, my discussion on the production of value in media and culture industries in Value and the Media: Cultural Production and Consumption in Digital Markets (Bolin 2011), and for reasons of space, I will at times refer the reader to more detailed discussions there.

\section{Justifying Theoretical Qualification}

Before elaborating a critique of field theory, we need to specify what relevance a qualification of Bourdieu's field theory would have in contemporary analyses of cultural or media production or consumption, since qualification without justification only would be an exercise in refined theoretical solipsism. Bourdieu himself always insisted on the empirical grounding of the field theory, and this was also the main reason why the theory developed over the years, as it was, on the one hand, adjusted to new empirical data, but also, on the other hand, adjusted to re-readings of old empirical material, as a return to a material always is made from a slightly different epistemological position. As Bourdieu argues in the preface to The Logic of Practice, the "progress of knowledge presupposes progress in our knowledge in the conditions of knowledge", which is why one needs to return to past objects in order to "objectify more completely one's objective and subjective relation to the object" (Bourdieu 1980/1990, 1). The same can be argued in relation to theory, as the advancement of theory requires that one constantly re-enters into the same theoretical realm from various empirical and epistemological positions.

One of the benefits of field theory is its insistence on the empirical grounding of theory, and that it in its multi-dimensionality opens for a discussion on, for example, media production from the perspective of other value forms than the economic (although it is at the same time obvious that Bourdieu himself did not take full advantage of this possibility). Arguably, field theory and the conceptual package around it, is of growing importance in today's fields of digital production and consumption. It can, for example, help us understand the relation between media users and media producers, and how the labour of media users at times becomes appropriated by and subsumed under value accumulation processes in professional media production. A main component in field theory is in fact that it seeks to overcome the analytical separation of production from consumption, which traditionally has been a major distinction in mass communication theory, where one of the major points in the characterisation of mass communication has been the separation of producers from consumers (cf. Wright 1959). Bourdieu was no media scholar, and did not live to see the media landscape of social networking services etc. But with the help of field theory, it is easy to see, for example, how the work of social distinction by consumers on e.g. social networking sites such as Facebook, becomes drawn into the field of production in quite other ways than the work of social distinction and difference was in the pre-digital age of cultural consumption and production (cf. Bolin 2012 forthcoming). This is important to emphasise, as the process of digitisation brings with it some important restructurings of the fields of production and consumption, some of which I will return to below (for example the possibilities of having media content distributed over several tech- 
nological platforms, and the possibility to extract economic value from productive consumption). However, when we look at these fields of consumption, it is also easy to see that the economistic bias of field theory poses problems, the idea of universal convertibility being one of them.

Now, if we against this background want to examine field theory more closely in order to refine the models presented there, we need to take our departure from the original model as presented by Bourdieu. A field is for Bourdieu the sphere, in which agents compete for a value that all involved agree on is worth struggling over: economic resources (money), political power, academic prestige, or artistic recognition. A field is relational, and the consecration of the value at stake in the field and the positions achieved are dependent on the consecrating power of the individuals and institutions with legitimacy to appoint these positions - those who with formal or informal authority can judge the game so to speak. In the field of cultural production, we not only have the cultural producers themselves (musicians, painters, authors and other cultural creators), but also critics, art institutions (museums, galleries, etc.), institutions for the training of artists (art schools, academies), and other institutions of consecration (art boards, foundations, prize committees, etc.), and so on. There is a value (or capital as Bourdieu says) at the centre of the field (art, in the case of the field of cultural production, but for other fields other values are at the centre of the struggle), and there are stakes to be made, strategies to be developed, and careers to be fulfilled.

According to Bourdieu (1977/1993), belief is the most foundational component in fields of production. Belief is the motor of the field dynamics and the ultimate product of the field. If one does not believe in the value at stake, one will not care for struggling over it. This means that the production of belief is also the production of value. Cultural producers naturally always justify their production in one way or another. If there is a belief system, there will also be arguments for its justification that are based on principles worked out in the field (principles and criteria of evaluation, for example). This fact, so foundational for the field analysis, is increasingly important in digital economies, since the absence of raw material in commodity production, and its intense dependence on labour, makes the price-setting mechanisms more diffuse for consumers. Digital non-tangible commodities, in contrast to tangible cultural artefacts such as a designed silver ring, are not constructed out of the combination of labour and raw material. This means that when products are composed of digits as a result of signifying practices, labour becomes even more important, as "the commodity, then, is only as good as the labour that goes into it", as Tiziana Terranova $(2000,48)$ puts it. This is why non-tangible commodities such as cultural and media products become more dependent on the belief in the commodities' specific value by customers, since there is no comprehensible material or physical base for it. The belief systems surrounding the design components in the production process are thus of crucial importance (something that indeed was observed already by economists such as John Kenneth Galbraith (1970), who argued that any market is built on systems of belief).

In Bourdieu's most elaborate account of the field of cultural production, based on the analysis of the literary field in France around 1900, Bourdieu (1992/1996) sketches the field as in figure 1 below. 


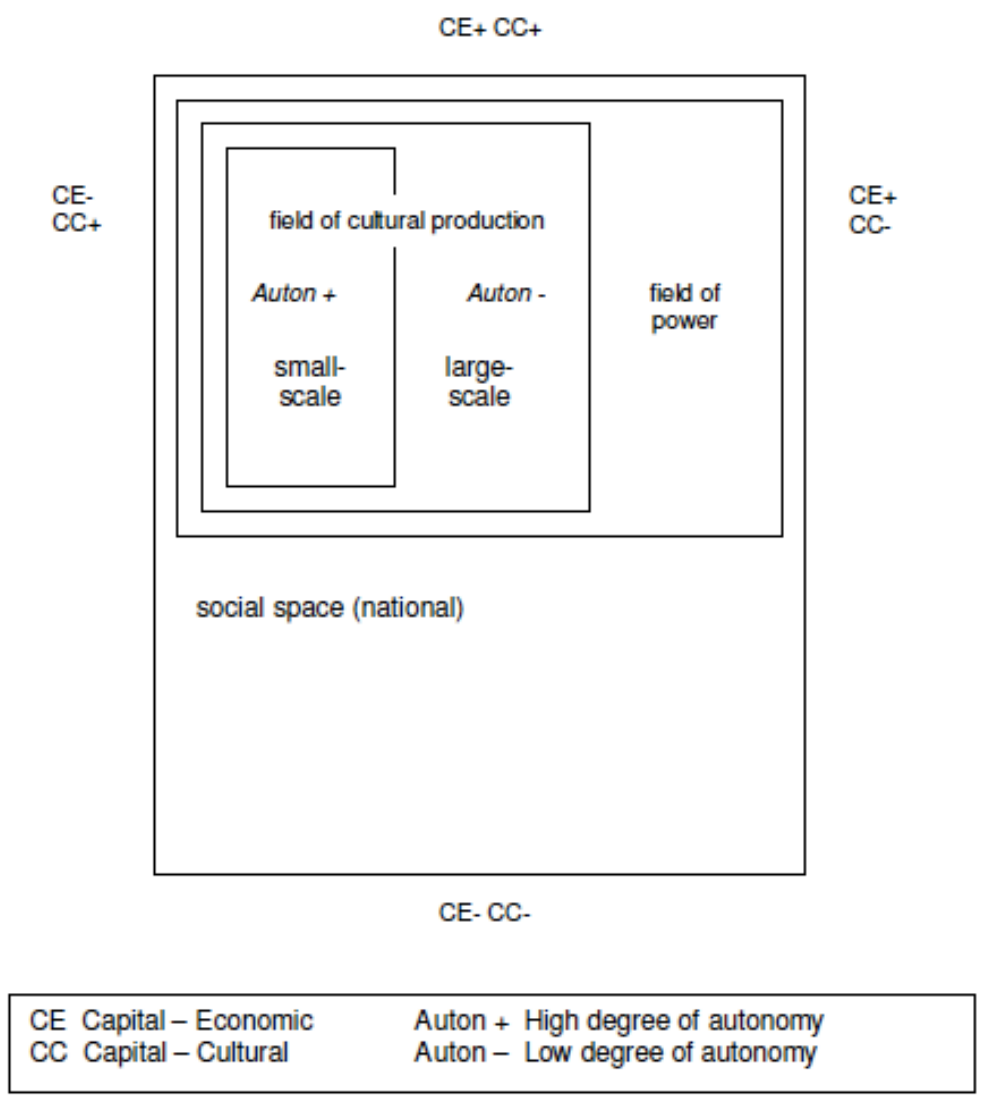

Figure 1: The field of cultural production in the field of power and in social space, based on Bourdieu (1992/1996, 124).

As has already been pointed out by many scholars (e.g. Benson 1999, Couldry 2003, Hesmondhalgh 2006), Bourdieu's interest was more in the left-hand side of the figure, in the field of small-scale production, restricted to a small circle of foremost other producers. This is on the one hand perfectly understandable, as it is here that the effects of the field are strongest, and the capital (or value) produced is the most pure. In this space, the logic of the field stands out as most powerful.

Now, if we want to redirect the attention to the other part of the figure, to the field of large-scale production as Bourdieu terms it, we quite soon find that there are some limitations to the model when it comes to explaining how the field capital is accumulated, the ways in which it is valued, and the strategies by which it is achieved. Firstly, as David Hesmondhalgh (2006) has argued, one might wonder if scale is the appropriate measure for the two sides of the field. As Bourdieu was more interested in analysing consecrated culture (the fine arts, literature), he never really made any detailed analyses of what he called large-scale production, and therefore he never observed the complexities within this part of cultural production, as Hesmondhalgh (2006) observes. And indeed, one need not think very long before one finds some very obvious exceptions that counter Bourdieu's claim: some of the most acclaimed artists actually have widespread popularity and are also economic successes: The books of the highly acclaimed Swedish author August Strindberg, to mention someone within the field of which Bourdieu theorises himself, were indeed already during his lifetime widely popular and sold well (see Ericson 2004), and The Beatles, The Beach Boys or Bob Dylan, to take Hesmondhalgh's $(2006,222)$ examples, also combine widespread popularity with elevated positions in the field.

Furthermore, Hesmondhalgh argues, the large-scale, or mass oriented part of the field might not be so undifferentiated as it might seem at a first sight. The media industry has for the past couple of decades become increasingly niche oriented, and while it might have once been true that the mass media strived for the largest possible audience, this is no longer so. Provoked by the external demand from advertisers, it is rather the case today that it is not the largest possible audience that 
is sought for, but the right audience (or the largest possible audience within the target niche group). Rationalisations and streamlining of production has led to an increased unwillingness on part of advertisers and sponsors to pay for "waste", that is, audience segments that view, read or listen without being of any use to them. For the advertiser who wants to reach 35000 "contacts" with 2125 year-old girls, all other groups are literally worthless, and the mere suspicion that broadcasters or publishers might charge for these "free-riders" is enough to make them start negotiating prices. This is also why some entertainment shows on television are actually too big for commercial companies. Therefore shows such as the Eurovision Song Contest are not of any interest to commercial broadcasters, since the audience is too big and undifferentiated and the prices of commercials are too high for niche-oriented advertisers.

A second problem is connected to Bourdieu's insistence on "the two fundamental principles of differentiation - economic capital and cultural capital" (Bourdieu 1992/1996, 344). The opposition between cultural and economic capital is certainly of great importance, but as Benson $(1999,485)$ argues, the opposition is also problematic. The emphasis on the dichotomous character of the structure obscures the fact that other kinds of value can be involved in the power struggles within the field. Non-commercial, public service television production cannot be explained by this model, for example, as stakes are not made to produce profit and success is not measured in terms of economic value. Public service television is instead more reliant on the production of political, and perhaps also educational, values in order to gain legitimacy for its activities and secure broadcasting licence agreements (cf. Bolin 2004). So, as the opposition is not between cultural and economic value, but rather between cultural and political/educational values, one should remember that the credo for public service broadcasters has always been to "inform, educate and entertain", following the original ideology laid out by John Reith 1924).

This leads to a third point, concerning the way in which Bourdieu places the field of cultural production in relation to the (national) field of power, as suggested in figure 1 above. In Bourdieu's model, the field of power consists of all the dominant positions across all fields of production (and consumption) in national space. However, this way of treating this quite heterogeneous group of agents as a field is not congruent with Bourdieu's own conceptualisation of a field as that space, in which agents compete for a type of capital (or value in my terminology) that they all consider as worthy. If we group together politicians, struggling for political power, with academics and corporate executives, who compete for quite different sorts of values, this group cannot be said to make up a field in Bourdieu's sense. In that respect it might be better to theorize several fields of power that are linked in mutual relations, each trying to force upon the other fields their respective "outer demand". In figure 2, I have tried to outline these relations schematically.

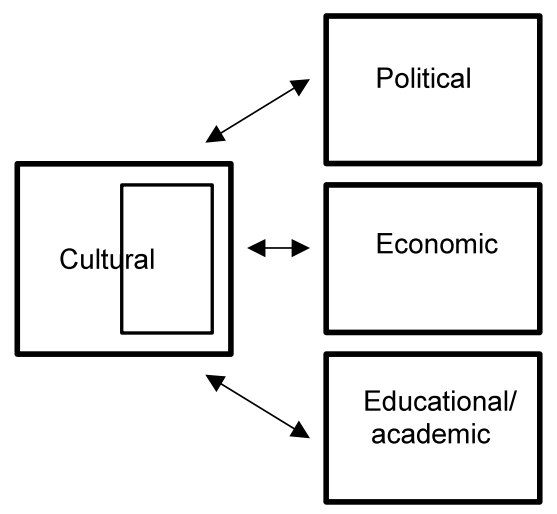

Figure 2: Outline of the relations between four fields of power.

Figure 2 is outlined from the perspective of the field of cultural production, where the right-hand side consists of what Bourdieu calls the subfield of large-scale production, or grande production as the French original reads. This is naturally the side, where popular culture, mass or, maybe more appropriately termed, unrestricted production and consumption occur. This production is unrestricted in the sense that it is not aimed at specific individual subjects or groups (other producers), but to each and everyone who wants to engage in these cultural products. In figure 2, this part of the field is closer to the other fields of power, indicating the subfield's greater pressures from the other fields of power in terms of demand. The subfield of restricted cultural production is more estranged and distant from forces of outer demand, and hence it has a greater amount of autonomy, 
which means that the value produced is to a much greater extent judged according to its own principles than in the case of the unrestricted subfield..

Now, after having given account of Bourdieu's field model and having suggested some qualifications to it, I want to turn to some of its influences and origins. In the next section I will thus account for its Marxist and Durkheimian legacy.

\section{The Marxist Legacy}

Bridget Fowler once described field theory as "an inventive elaboration of Marxist materialism", while simultaneously owing "inheritance from Durkheim's idea that men and women generate classifications of the world, doxa, which have their roots in social divisions, but which have a profound influence in the form of their basic beliefs about the social game" (Fowler 2006, 113). And it is indeed true that Bourdieu is more influenced by Marx than is usually acknowledged (Fowler being an exception, but see also Thompson 1991). In interviews and in his books, he strongly disassociates himself from Marx (although at the same time acknowledge having read him carefully e.g. Bourdieu 1990; Bourdieu \& Wacquant 1992). However, he firmly refuses to acknowledge any wide influence from him, despite the fact that there are several instances in Bourdieu's theoretical thinking that actually owes more than just a little to Marx. The most explicit influences are perhaps revealed in the widely cited article "The Forms of Capital" (1983/1986). Capital, he argues, appear in three forms: social, cultural, and economic. The basis for this capital, he explains: "Capital is accumulated labor (in its materialized form or its 'incorporated', embodied form) which, when appropriated on a private, i.e., exclusive basis by agents or groups of agents, enables them to appropriate social energy in the form of reified or living labor" (Bourdieu 1983/1986, 241).

This quote is very close to some of the original formulations by Marx, for example when he in Capital writes that "all commodities, as values, are objectified human labour" (Marx 1867/1976, 188). The difference between the two quotes should be noted, and where Bourdieu argues that capital is accumulated labour, Marx holds that it is value that is the reified (and accumulated, one would presume) labour.

The influence of Marxist thought in the field theory of Bourdieu is also accompanied by sociological and anthropological theories of symbolic exchange. By incorporating theories of symbolic exchange, Bourdieu transgress the theoretical framework of Marxism, which makes it possible for him to extend his thinking to other kinds of economies, such as gift economies. The main inspiration in this respect comes from Émile Durkheim's The Elementary Forms of Religious Life (Durkheim 1912/2001), in which Durkheim developed thoughts on the sacred in society, that is, those principles that govern social belief systems, making up the foundations of society. These thoughts were later further developed by Durkheim's younger colleague Marcel Mauss in The Gift (Mauss 1925/1990), where he theorized symbolic exchange. The theory of symbolic exchange is a theory of social relations and societal integration. The gift and the counter-gift are acts of communication and confirmation of social status, and have the dual status of being "both positive communication and agonistic confrontation" (Merrin 2005, 14).

It is thus not hard to see the influences of Durkheim and Mauss in Bourdieu's analysis of the "logic of social exchanges" (Bourdieu 1983/1986, 253) within fields of cultural production and consumption. And just as Durkheim had argued that belief systems are not merely cognitive in that they help us think, but that they are also systems that makes us act, Bourdieu's theory is a theory of action, explaining why social individuals act in certain specific ways rather than others. Action, in fact, has its basis in belief. This is the analogy that Durkheim gives in order to explain not only traditional archaic societies, but also his contemporary social world: "The worshipper who has command with his god is not only a man who sees new truths that the unbeliever does not know; he is a man who is capable of more", as Durkheim (1912/1990: 311) argues in his conclusion.

The influences from Durkheim and Mauss bring with them a structuralist element, based in relational thinking, which allows Bourdieu to deal with the production of several kinds of symbolic values. However, although especially Mauss uses some economic concepts in his theory of symbolic exchange (e.g. 'interest'), Bourdieu more systematically models his theory on economic metaphors, such as capital, markets, labour, etc.

In the introduction to the edited collection Language and Symbolic Power (Bourdieu 1991), the editor John B. Thompson (1991) briefly discusses Bourdieu's relation to Marxist terminology and argues that although there are obvious influences when it comes to the concepts used, these influences are rather on the level of the epistemological and methodological approach and that Bourdieu does not so much adopt and use the conceptual framework in any un-reflected way, but rather reworks it, and also does so in relation to influences from the sociology of societal integration 
of Durkheim, the structural anthropology of Lévi-Strauss, the gift economy of Mauss, and the phenomenology of the body of Merleau-Ponty.

There is of course a lot of truth to this, but one can in contrast to Thompson also argue that the influences from Marx in Bourdieu's works go deeper than that, and that the ways in which Bourdieu adopts concepts and ideas from Marx also produces some of the problems in his theory. This is especially so as this approach leads him into using economic metaphors and concepts. One of the more problematic conceptual influences that Bourdieu has incorporated into his theory is the idea of convertibility between capital forms: "The universal equivalent, the measure of all equivalences, is nothing other than labor-time (in the widest sense); and the conservation of social energy through all its conversions is verified if, in each case, one takes into account both the labor-time accumulated in the form of capital and the labor-time needed to transform it from one type into another" (Bourdieu 1983/1986, 253).

This quote can be compared with a formulation by Marx in Capital, Volume 1: "Because all commodities, as values, are objectified human labour, and therefore in themselves commensurable, their values can be communally measured in one and the same specific commodity, and this commodity can be converted into the common measure of their values, that is into money. Money, as a measure of value is the necessary form of appearance of the measure of value which is immanent in commodities, namely labour-time" (Marx 1867/1976, 188).

We shall note here that for Marx, objectified human labour is immanent in the commodity. Money, however, can represent this value, and through money a measure is given to the value of commodities. So while it is true that the root of value is labour, "hidden" in the commodity, it is only through its representation - money (or gold that Marx sees as "the universal measure of value") that the exact measure (price) is set. Labour as a commodity can only be converted through this universal measure, money, but as Marx says, "money does not in itself directly represent labourtime" (Marx 1867/1976, 188, note 1). Money represents value, but is also that tool that quantifies value. Money, then, is the universal equivalent, not labour.

We shall note this because although Bourdieu uses Marxian-inspired economic concepts only as analogy, as Thompson argues, analogies also signify something. Analogies are not innocent, they have effects on our ways of apprehending the world around us, and thus have social and material effects, quite in line with the structuralist thinking that says that language actually produces our reality that Bourdieu himself adopted in Language and Symbolic Power (Bourdieu 1991).

\section{Capital or Value?}

Bourdieu often returns to the observation that the field of cultural production is increasingly threatened by the "world of money" (e.g. Bourdieu 1992/1996, 344), no matter whether this concerns the cultural production of television and journalism or the production of art and consecrated culture (see also: Bourdieu 1998 and 2001). Other contemporary intellectuals naturally share this critique of commercialisation, although Bourdieu's critique of market forces is phrased with his own specific terminology and relates to his analysis of the successive introduction and rise of the fields of cultural and academic production. The relative autonomy these fields have gained has, as he argues, been conquered through a continuous struggle, and he sees this autonomy as threatened by forces of the economy today.

However, although it is easy to side with Bourdieu in his criticism of the market forces upon other fields in society, this insistent emphasis on the tension between culture and the economy does not help us explain the wealth of forces that shape the dynamics in fields such as the field of political power, centred on the belief in other value forms. Neither does it explain all the tensions even within the field of cultural production, as I have tried to show above. Undoubtedly, the economic field of power is very strong, but it is not all compassing.

A more serious problem, however, is that Bourdieu never really enters a serious discussion with Marx on value, which is a term he rarely uses, and capital, which is a concept he indeed uses, but does not actually theorise in any clear-cut manner. When Bourdieu theorises social, cultural, economic capital, he actually never explains how this capital can be set to work in the productionconsumption process, how it can be re-invested, etc. It seems in fact as if he confuses value and capital in his theory. When he discusses the three forms of capital (Bourdieu 1983/1986), he is actually speaking about value. In order for value to become capital, according to Marx, it has to be set in motion, ultimately producing surplus value or profit (which can then be reintroduced in the production-consumption circuit, producing again more value, etc.). When Bourdieu argues that "capital is accumulated labor", he reproduces a misconception of Marx, who stated that "by incorporating living labour into their lifeless objectivity, the capitalist simultaneously transforms value. 
i.e. past labour in its objectified and lifeless form, into capital, value which can perform its own valorisation process" (Marx 1867/1976, 302).

So, what Bourdieu really proposes, but fails to conceptually capture, is that the acquired abilities and dispositions that form a person's habitus, the accumulated labour objectified in the person in "embodied form", is value rather than capital, and the process Bourdieu does not discuss is the valorisation process by which this value is turned into re-investable capital, that is, value set to work. By re-introducing the distinction between value and capital in the field model, we can also distinguish between value as "standards, criteria or measures" (as philosopher Douglas Magendanz [2003] describes value) which also helps analysing dynamics in fields of consumption, and capital, as it is this value put to work in the process of valorisation that ultimately produces surplus (for example, the acquirement of a more elevated or legitimate position in the field of cultural consumption).

However, and given the bias of economic value in discussions of value in general, there is a profound risk that the language adopted from the field of the economy is counter-productive to the aims of Bourdieu's field analysis, his criticism of market logics, and his insistence on the autonomy of the fields of cultural, academic and other production. Autonomy is for Bourdieu the founding basis for the generation of the field's specific value (or capital, as Bourdieu would say), the principles for its accumulation, and the specificities of its working in the field. Bourdieu's choice of terminology, adopted from the sphere of economics, might in fact do what he fears the most: subsuming every value form to the economic logic. The act of insisting on the convertibility of capital between fields is actually reductive if seen in relation to the various value forms in fields of cultural production and consumption. He is actually making capital the "universal equivalent" in the same manner as money. Furthermore, cultural capital cannot be reduced to a quantitative entity in the same way as money can. It is a quality, not a quantity. If one wanted to be hard on Bourdieu, one could say that he helps advancing this process by further confirming the idea that it is the economy in the last instance that is decisive.

\section{Conclusion}

My argument is not that we should abandon the field model, but that we need to qualify it in two ways. Firstly, we need to modify the model and differentiate between several fields of power in society, rather than one singular field of power, as Bourdieu argued in The State Nobility (Bourdieu 1996). This assumption is important for media and communication researchers because contemporary media production is becoming increasingly complex, involving both commercially driven production (aiming at economic profit), as well as non-profit motivated production through, for example, user-generated contents on social networking sites, blogs, citizen journalism, fan production and amateur media production more generally. Often these profit-motivated as well as non-profit motivated efforts are involved in the very same phenomena, and, as I have analysed at more length elsewhere (Bolin 2011, 2012), these production phenomena cannot be understood solely through an economic analysis or one that structures the analysis through the opposition between the cultural and the economic. Even the structure of European television production cannot be understood through this dual tension between culture and economy, as European television production also involves public service broadcasting, not aiming for profit (that is, where success is not measured in economic terms, but in social and political terms) (cf. Bolin 2004).

Secondly, we need to distinguish between value - that which is produced in the continuous struggles within fields of cultural production/consumption - and capital - as value set in motion in order to produce profits. It has been my argument that the roots of Bourdieu's theory in Marx' labour theory of value poses some problems for him (especially his theory of convertibility between forms of capital). This point relates to the first point above, since we can only understand the specific value forms of each field in relation to the belief system (the value system) of each empirical relation in these fields. When the tension is between culture and the economy, this might work (if even there), but when analysing fields where the tensions involve other strong forces (beliefs), for example the social or academic fields, we need to acknowledge also these other structuring forces or logics that have a bearing on the specific character of the field struggle.

Furthermore, on a normative note, we should not repeat Bourdieu's mistake (derived from the Marxist legacy in his theory) to over-emphasize the economic as the determining factor in the last instance, but rather defend the autonomous status of aesthetic, academic, cultural and social values that result from struggles and negotiations in fields of cultural production. A truly autonomous field of cultural production (and academic production) could just as well have its value influence on other fields - in the same way as the economic field today influences all other fields. This would indeed be a counter force to the tendencies of universal market domination. 


\section{References}

Benson, Rodney. 1999. Field Theory in Comparative Context: A New Paradigm for Media Studies. Theory and Society 28 (3): 463-498.

Benson, Rodney, and Eric Neveu, eds. 2005. Bourdieu and the Journalistic Field. Cambridge: Polity.

Bolin, Göran. 2004. The Value of Being Public Service: The Shifting of Power Relations in Swedish Television Production. Media, Culture \& Society 26 (2): 277-287.

Bolin, Göran. 2009. Symbolic Production and Value in Media Industries. Journal of Cultural Economy 2 (3): 345-361.

Bolin, Göran. 2011. Value and the Media: Cultural Production and Consumption in Digital Markets. Farnham: Ashgate.

Bolin, Göran. 2012. The Forms of Value: The Two Active Audiences, Information, Communication \& Society 15.

Bourdieu, Pierre. 1977/1993. The Production of Belief: Contribution to an Economy of Symbolic Goods. In The Field of Cultural Production. Essays on Art and Literature, 74-111. Cambridge: Polity, forthcoming.

Bourdieu, Pierre. 1983/1986. The Forms of Capital. In Handbook of Theory and Research for the Sociology of Education, edited by John G. Richardson, 241-258. New York: Greenwood Press.

Bourdieu, Pierre. 1990. In Other Words: Essays Towards a Reflexive Sociology. Cambridge: Polity.

Bourdieu, Pierre. 1991. Language and Symbolic Power. Cambridge: Polity.

Bourdieu, Pierre. 1992/1996. The Rules of Art: Genesis and Structure of the Literary Field. Cambridge: Polity.

Bourdieu, Pierre. 1993. The Field of Cultural Production: Essays on Art and Literature. Cambridge: Polity.

Bourdieu, Pierre. 1996. The State Nobility: Elite Schools in the Field of Power. Cambridge: Polity.

Bourdieu, Pierre. 1998. Acts of Resistance: Against the Tyranny of the Market. New York: The New Press.

Bourdieu, Pierre. 2001. Contre-feux 2. Paris: Raison D'Agir.

Bourdieu, Pierre, and Loïc J.D. Wacquant. 1992. An Invitation to Reflexive Sociology. Cambridge: Polity.

Couldry, Nick. 2000. The Place of Media Power: Pilgrims and Witnesses of the Media Age. London: Routledge.

Couldry, Nick. 2003a. Media Rituals: A Critical Approach. London: Routledge.

Couldry, Nick. 2003b. Media Meta-Capital: Extending the Range of Bourdieu's Field Theory. Theory and Society 32 (5/6): 653-677.

Durkheim, Émile. 1912/2001. The Elementary Forms of Religious Life. Oxord: Oxford University Press.

Ericson, Staffan. 2004. Två Drömspel. Från Strindbergs Modernism till Potters Television. Stockholm: Brutus Östlings Bokförlag Symposion.

Fowler, Bridget. 2006. Autonomy, Reciprocity and Science in the Thought of Pierre Bourdieu. Theory, Culture \& Society, 23 (6): 99-117.

Galbraith, John Kenneth. 1970. Economics as a System of Belief. American Economic Review 60 (2): 469-478.

Hallin, Daniel, and Paolo Mancini. 2004. Comparing Media Systems: Three Models of Media and Politics. New York: Cambridge University Press.

Hesmondhalgh, David. 1996. Flexibility, Post-Fordism and the Music Industries. Media, Culture \& Society 15 (3): 469-88.

Hesmondhalgh, David. 1999. Indie: The Institutional Politics and Aesthetics of a Popular Music Genre. Cultural Studies 13 (1): 34-61.

Hesmondhalgh, David. 2006. Bourdieu, the Media and Cultural Production. Media, Culture \& Society 28 (2): 211-231.

Magendanz, Douglas. 2003. Conflict and Complexity in Value Theory. The Journal of Value Inquiry 37: 443-453.

Marx, Karl. 1867/1976. Capital. A Critique of Political Economy. Volume One. London: Penguin Books.

Mauss, Marcel. 1925/1990. The Gift: The Form and Reason for Exchange in Archaic Societies. London: Routledge.

Merrin, William. 2005. Baudrillard and the Media. Cambridge: Polity Press.

Reith, John. 1924. Broadcast over Britain. London: Hodder \& Stoughton.

Schultz, Ida. 2005. Bag om nyhedskriterierne. En etnografisk feltanalyse af nyhetsværdier i journalistisk praksis. Roskilde: Institut for Kommunikation, Journalistik og Datologi.

Terranova, Tiziana. 2000. Free Labor: Producing Culture for the Digital Economy. Social Text, 18 (2): 33-58.

Thompson, John B. 1991. Editor's Introduction. In Language and Symbolic Power, by Pierre Bourdieu, 1-31. Cambridge: Polity.

Wright, Charles R. 1959. Mass Communication: A Sociological Perspective. New York: Random House.

\section{About the Author}

\section{Göran Bolin}

is Professor of Media and Communication Studies at Södertörn University, Stockholm, Sweden. Bolin's current research interests are focussed on cultural production and consumption in contemporary culture industries, and the effects of on the relationship between these provoked by digitization and marketization processes. His most recent work is summarised in Value and the Media: Cultural Production and Consumption in Digital Markets (Ashgate, 2011). An edited volume on Cultural Technologies. The Shaping of Culture in Media and Society (Routledge) will appear in 2012. He is an editor of Young (Sage), and on the editorial board of several other international peer review journals. 